Corrigendum: Recessive tolerance to preproinsulin 2 reduces but does not abolish type 1 diabetes

Elmar Jaeckel, Myra A Lipes \& Harald von Boehmer

Nature Immunology 5, 1028-1035 (2003).

On page 1034, line 12, reference 40 should be reference 37.

The labels Bfl-1 and Bcl-2 for Figure 4a were reversed. The figure is labeled correctly here.

a

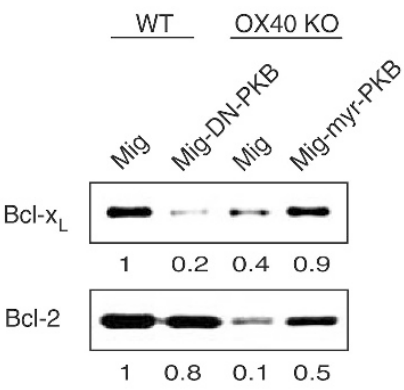

Bfl-1

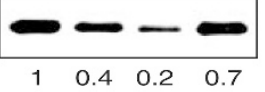

$\beta$-actin

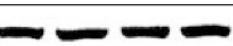




\section{Erratum: Signaling by the kinase MINK is essential in the negative selection of autoreactive thymocytes}

Nami McCarty, Silke Paust, Koichi Ikizawa, Ippeita Dan, Xiaoyan Li \& Harvey Cantor

Nature Immunology 6, 65-72 (2005)

On page 70, line 28 should read “...IL-7 receptor-positive CD $4{ }^{\text {lo }} \mathrm{CD} 8$ hi (refs. 34,35).” Nature Immunology regrets this error.

Errata:

Nature Immunology 5, 1190 (2004).

The two corrigenda on page 1190 in the November 2004 issue (volume 5, issue 11) gave incorrect publication dates. Those should be 2004.

Nature Immunology regrets this error.

\section{Erratum and corrigendum: Innate and adaptive immunity:} specificities and signaling hierarchies revisited

Eric Vivier \& Bernard Malissen

Nature Immunology 6, 17-21 (2005)

On page 18, Figure 1 was incorrect. The correct figure is presented here. Nature Immunology regrets this error.

On page 19, in the legend to Figure 3, line 7 should read "(such as CD19, NKG2D or integrins)...."

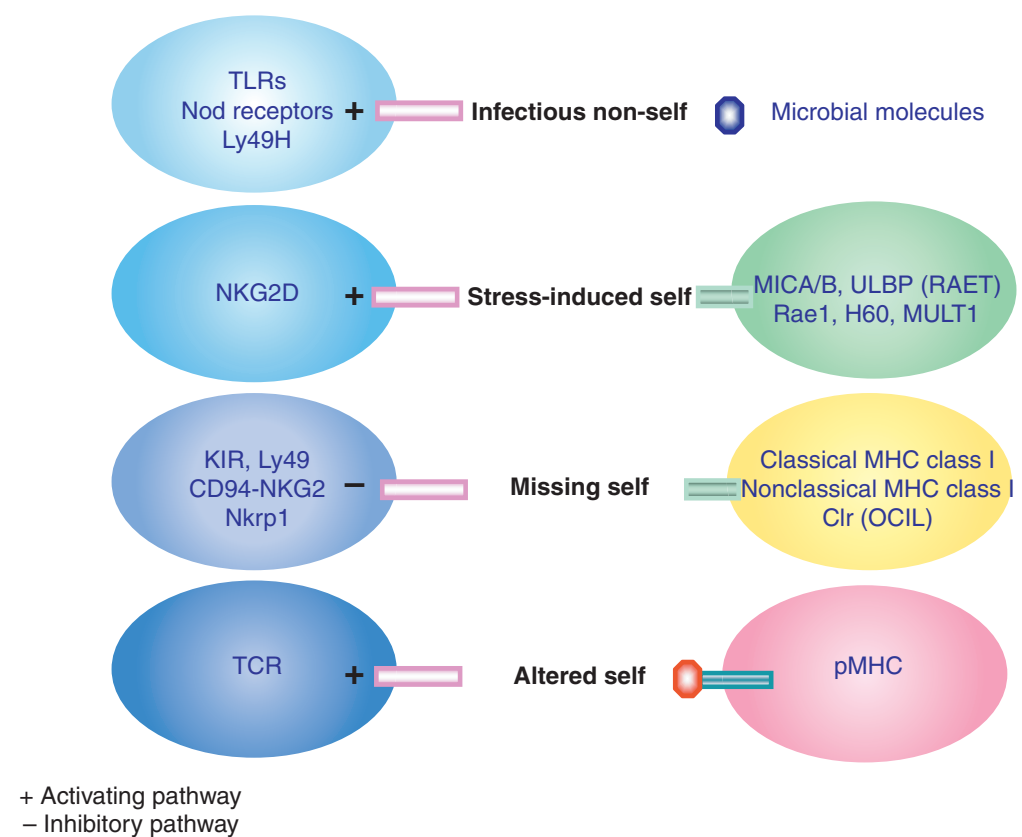

Corrigendum: Building an antibody factory: a job for the unfolded protein response

Joseph W Brewer \& Linda M Hendershot

Nature Immunology 6, 23-29 (2005)

On page 26, lines 20 and 21 should read “...CHOP (also known as DDIT3 or GADD153)...” 